\title{
MEDIDAS ESPAÑOLAS DE ORDEN LABORAL Y SOCIAL FRENTE A LA PANDEMIA DEL COVID-19*
}

\author{
Iván Antonio RodRíGUEz CARDO \\ Profesor Titular de Derecho \\ del Trabajo y de la Seguridad Social \\ Facultad de Derecho. Universidad de Oviedo \\ Experto Nacional en la European \\ Labour Law Network \\ rodriguezivan@uniovi.es
}

\section{INTRODUCCIÓN}

La Ley Orgánica 4/1981, de 1 de junio, desarrolla el art. 116 CE, y en su art. 4 permite al Gobierno declarar el estado de alarma cuando se materialice alguna de las circunstancias previstas en los siguientes apartados: «b) Crisis sanitarias, tales como epidemias y situaciones de contaminación graves; c) paralización de servicios públicos esenciales para la comunidad, cuando no se garantice lo dispuesto en los artículos veintiocho, dos, y treinta y siete, dos, de la Constitución, o concurra alguna de las demás circunstancia o situaciones contenidas en este artículo, y $d$ ) situaciones de desabastecimiento de productos de primera necesidad». Ese marco normativo justificó que el 14 de marzo de 2020 el Gobierno declarara el estado de alarma para hacer frente a las consecuencias del COVID-19, cuya rápida propagación y singular virulencia dificultaban la respuesta sanitaria por falta de medios, tanto a efectos de prevención como de tratamiento eficaz.

El propósito principal, precisamente, consistía en reducir el ritmo de contagios para aliviar la presión sobre el sistema sanitario. A tal fin, se consideraba imprescindible aumentar la distancia social para dificultar la transmisión del virus y una medida de esa índole provoca un impacto en todos los órdenes de la vida, tanto personal como profesional. La organización social y económica se ve necesariamente afectada si las personas no pueden aproximarse a menos de una determinada distancia.

En ese contexto, el Real Decreto 463/2020, de 14 de marzo, por el que se declara el estado de alarma para la gestión de la situación de crisis sani-

* El presente estudio se cerró a fecha de 30 de abril de 2020. 
taria ocasionada por el COVID-19, imponía una «limitación de la libertad de circulación de las personas» (art. 7), aunque permitía los desplazamientos «al lugar de trabajo para efectuar su prestación laboral, profesional o empresarial» [apartado 1.c)]. Sin embargo, ese desplazamiento estaba supeditado a que el empleador pudiera continuar con su actividad empresarial o comercial, lo que no siempre era posible.

En efecto, el art. 10 de ese Real Decreto 463/2020 exigía la suspensión de una serie de actividades o negocios por considerar alto el riesgo de contagio, como sucedía con los locales y establecimientos minoristas (salvo en sectores esenciales, como alimentación o sanidad, entre otros); los destinados a cultura, deporte y ocio; la hostelería y restauración, excepto entrega a domicilio, y la actividad educativa presencial (art. 9 del RD 463/2020).

Tras ese primer periodo el Estado de alarma fue prorrogado sucesivamente, pero las condiciones cambiaron en función de la evolución de la epidemia. El Real Decreto-ley 10/2020, de 29 de marzo, inició una segunda etapa marcada por restricciones más intensas, pues el Gobierno se decantó por un confinamiento estricto y únicamente se admitía la continuidad de las actividades calificadas como esenciales en un listado elaborado al efecto (y susceptible de modificación sobrevenida por el propio Gobierno), debiendo suspenderse el resto. Resultaba ya evidente en ese momento que la duración del estado de alarma se prolongaría más allá de lo inicialmente anunciado, pero que la intensidad de las restricciones a la movilidad y a la actividad económica resultaría variable y dependería de la evolución de la pandemia.

El 13 de abril finalizó ese periodo de confinamiento más estricto, pero el estado de alarma se prorrogó y la suspensión de actividades presenciales retornó a los términos iniciales, aunque con alguna particularidad. Por ejemplo, el sector de la construcción, que debió cesar temporalmente durante esa primera mitad del mes de abril, reanudó la actividad, pero la Orden SND/340/2020, de 12 de abril, mantuvo la suspensión de las obras en edificios habitados, porque la interacción en zonas comunes entre los trabajadores y los residentes incrementaba el riesgo de contagio.

En este contexto, la actividad económica se redujo notablemente durante el estado de alarma, bien por la suspensión de determinadas actividades, bien por las propias consecuencias del confinamiento. No es extraño, así pues, que muchas empresas hayan debido adoptar medidas de carácter laboral en forma de reducción o modificación de condiciones de trabajo, y principalmente de jornada, aunque también medidas de mayor calado, como suspensiones o extinciones de contratos. Más de cua- 
tro millones de trabajadores se han visto afectados directamente por las regulaciones de empleo, y por ello el Gobierno ha introducido mecanismos específicos de protección.

Las medidas más relevantes adoptadas hasta ahora consisten en la preferencia por el trabajo a distancia para facilitar la continuidad del mayor número de actividades profesionales posible reduciendo el riesgo, la mal llamada «prohibición de despidos» durante el estado de alarma y la incentivación de la flexibilidad interna (modificación de condiciones de trabajo y suspensión de contratos), calificando a tal efecto la emergencia sanitaria como una causa de fuerza mayor. Desde el plano de la Seguridad Social, se amplía el ámbito subjetivo y se reducen las exigencias de la protección por desempleo para atender todas las nuevas situaciones de necesidad. Las siguientes líneas no pretenden ofrecer un análisis detallado de todas esas medidas - lo que es prematuro en el estadio actual—, sino dar cuenta de las novedades que se han ido produciendo, sistematizándolas e identificando líneas de tendencia, con el fin de proporcionar una primera aproximación y poner de manifiesto algunos desajustes o carencias en un plano estrictamente técnico.

\section{EL TRABAJO EN TIEMPO DE CONFINAMIENTO: APUESTA POR EL TRABAJO A DISTANCIA Y POR LA FLEXIBILIDAD INTERNA}

La limitación de la libertad de circulación de las personas durante el estado de alarma no implica una paralización total de la actividad económica ni exige que la producción cese temporalmente. Por un lado, la suspensión se concentró en determinados sectores y no se extendió a la totalidad de la actividad profesional, comercial o industrial. Por otro, la decisión gubernativa no implicaba necesariamente un cese temporal del negocio, sino únicamente de las actividades presenciales, pues el fin consistía en minimizar el riesgo de propagación de la enfermedad. Precisamente por ello, se admitía la continuidad de cualesquiera actividades profesionales, comerciales o industriales que pudieran desarrollarse sin esa necesidad de proximidad, y para ello el art. 5 del Real Decreto-ley 8/2020, de 17 de marzo, declaraba el «carácter preferente del trabajo a distancia», aunque más bien «a domicilio», pues pocas opciones más caben en un contexto de confinamiento. Lógicamente, las empresas debían «adoptar las medidas oportunas si ello es técnica y razonablemente posible y si el esfuerzo 
de adaptación necesario resulta proporcionado». El trabajo a distancia se considera una alternativa prioritaria frente a medidas de ajuste, como suspensiones de contratos o reducciones del tiempo de trabajo.

En verdad, la promoción del teletrabajo es muy razonable en este contexto de crisis sanitaria, pero conviene precisar que no se ha modificado el art. 13 del Estatuto de los Trabajadores (en adelante, ET), que exige un acuerdo escrito para articular esta modalidad de prestación de servicios. El Real Decreto-ley 8/2020 no parece considerar necesario el consentimiento del trabajador, y también minimiza las medidas de prevención, pues la evaluación de riesgos se entiende cumplida «a través de una autoevaluación realizada voluntariamente por la propia persona trabajadora». Son, en cualquier caso, excepciones comprensibles en el contexto de emergencia sanitaria, especialmente porque la norma se diseña desde el convencimiento de que determinados sacrificios son aceptables para la consecución de un interés prevalente en este caso, como es el mantenimiento de la actividad allí donde las posibilidades técnicas lo permitan.

Ahora bien, el trabajo a distancia no siempre se convierte en una opción viable, porque no es una modalidad operativa en cualesquiera sectores y profesiones. Además, el estado de alarma no derivó en una suspensión de toda actividad presencial, sino que muchas de ellas pudieron continuar, aunque con reglas particulares en relación sobre todo con el tiempo de trabajo. La flexibilidad interna se potencia con el objetivo de evitar medidas más traumáticas. La fuerza mayor y las causas económicas, organizativas, técnicas o de producción permiten la adopción de medidas de ajuste temporal, como la reducción temporal de la jornada - compensando la reducción salarial con la protección por desempleo-, y permiten eludir suspensiones y, sobre todo, extinciones de contratos.

En el ámbito del empleo público, y principalmente en el contexto del funcionamiento de los servicios esenciales, las medidas de adaptación se han configurado en ocasiones con mucha amplitud, pues algunas Comunidades Autónomas han atribuido a la Administración empleadora facultades que casi cabría calificar como exorbitantes en relación con la movilidad funcional y geográfica y la modificación del tiempo de trabajo. Además, las reglas de contratación de nuevo personal se relajan notablemente para garantizar la continuidad del servicio ${ }^{1}$.

\footnotetext{
${ }^{1}$ A modo de ejemplo, y en relación con Navarra, vid. Decreto-ley Foral 1/2020, de 18 de marzo, por el que se aprueban medidas urgentes para responder al impacto generado por la crisis sanitaria del coronavirus (COVID-19), y Ley Foral 6/2020, de 6 de abril, por la que
} 
No obstante, y en relación con la adaptación del tiempo de trabajo, no siempre la iniciativa se concede al empleador, sino que se han atribuido nuevos derechos de conciliación al trabajador. En efecto, el art. 6 del Real Decreto 8/2020 contempla una regulación específica que tras el Real Decreto-ley 15/2020 ha recibido la denominación de «Plan MECUIDA». Concretamente, los trabajadores que «acrediten deberes de cuidado respecto del cónyuge o pareja de hecho, así como respecto de los familiares por consanguinidad hasta el segundo grado», pueden solicitar — como auténtico derecho- la adaptación y/o reducción de jornada «cuando concurran circunstancias excepcionales relacionadas con las actuaciones necesarias para evitar la transmisión comunitaria del COVID-19».

Esas circunstancias excepcionales implican que el trabajador debe prestar los cuidados oportunos a uno de los familiares antes mencionados debido, por ejemplo, al cierre de centros educativos o al hecho de que «la persona que hasta el momento se hubiera encargado del cuidado o asistencia directos de cónyuge o familiar hasta segundo grado de la persona trabajadora no pudiera seguir haciéndolo por causas justificadas relacionadas con el COVID-19».

La reducción de jornada tiene condiciones distintas a las previstas con carácter general en el art. $37 \mathrm{ET}$, pues puede alcanzar excepcionalmente el 100 por 100 , mientras que la adaptación del tiempo de trabajo se configura de manera muy amplia, hasta el punto de que, pese al tenor literal del precepto, los cambios no afectan exclusivamente a la jornada. El catálogo de posibilidades es extenso, pues la adaptación «puede consistir en cambio de turno, alteración de horario, horario flexible, jornada partida o continuada, cambio de centro de trabajo, cambio de funciones, cambio en la forma de prestación del trabajo, incluyendo la prestación de trabajo a distancia, o en cualquier otro cambio de condiciones que estuviera disponible en la empresa o que pudiera implantarse de modo razonable y proporcionado».

Aunque en principio se diseña como un derecho del trabajador, pues la «concreción inicial corresponde a la persona trabajadora, tanto en su alcance como en su contenido, siempre y cuando esté justificada, sea razonable y proporcionada, teniendo en cuenta las necesidades concretas de cuidado que debe dispensar la persona trabajadora, debidamente acreditadas, y las necesidades de organización de la empresa», ese art. 6 del Real Decreto-ley 8/2020, en su apartado 2 , precisa que «empresa y persona tra-

se aprueban medidas urgentes para responder al impacto generado por la crisis sanitaria del coronavirus (COVID-19). 
bajadora deberán hacer lo posible por llegar a un acuerdo», lo que, desde luego, plantea incertidumbres sobre la efectividad del derecho en defecto de pacto. En apariencia, mientras la reducción de jornada es un auténtico derecho, la adaptación sí parece requerir la aquiescencia del empleador, que no podrá negarse a la solicitud del trabajador, pero sí a la concreta adaptación exigida cuando se demuestre algún perjuicio organizativo, debiendo canalizarse las discrepancias a través del procedimiento previsto en el art. 139 de la Ley General de la Seguridad Social (en adelante, LGSS) cuando el conflicto se judicialice.

Finalmente, conviene tener presente que estas medidas de carácter excepcional destinadas a facilitar la continuidad de la actividad económica - trabajo a distancia, reducción de jornada o adaptación de las condiciones de trabajo- podrán mantenerse no solo durante el estado de alarma, sino durante los tres meses posteriores a su finalización, porque el art. 15 del Real Decreto 15/2020, de 21 de abril, extendió durante dos meses adicionales la duración inicial prevista en la disposición adicional décima del Real Decreto-ley 8/2020 («hasta un mes después del fin de la vigencia de la declaración del estado de alarma»).

\section{PROHIBICIÓN DE DESPIDOS Y FACILIDADES PARA LA REGULACIÓN TEMPORAL DEL EMPLEO}

Las restricciones a la movilidad fueron adoptadas ante una circunstancia extraordinaria, una emergencia sanitaria, y vinieron acompañadas de medidas también extraordinarias con el propósito de reducir el impacto negativo sobre la actividad económica y el empleo. Por supuesto, se asume como premisa de partida que tales medidas van a tener una duración temporal y que el objetivo consiste en retornar a la normalidad lo antes posible; objetivo, por cierto, que también está presente en normas autonómicas que adaptan los programas de fomento del empleo a esta situación excepcional ${ }^{2}$.

En ese contexto, y como se desarrollará a continuación, el Real Decretoley $8 / 2020$ facilitó la invocación de la fuerza mayor como causa de medi-

2 Por ejemplo, en Andalucía, vid. Decreto-ley 10/2020, de 29 de abril, por el que se establecen medidas extraordinarias y urgentes de flexibilización administrativa en materia de ayudas en el ámbito del empleo y medidas complementarias con incidencia en el ámbito económico, local y social como consecuencia de la situación ocasionada por el coronavirus (COVID-19) (BOJA, 29 de abril de 2020). 
das laborales durante el estado de alarma, pero las evidencias demostraron muy pronto que el despido por fuerza mayor o por otras causas empresariales podía derivar en una fuerte destrucción de empleo, lo que motivó que el art. 2 del Real Decreto-ley 9/2020, de 27 de marzo, declarase que «la fuerza mayor y las causas económicas, técnicas, organizativas y de producción en las que se amparan las medidas de suspensión de contratos y reducción de jornada previstas en los arts. 22 y 23 del Real Decreto-ley 8/2020, de 17 de marzo, no se podrán entender como justificativas de la extinción del contrato de trabajo ni del despido» ${ }^{3}$. El empleador, por tanto, estaba facultado para acudir a medidas de regulación temporal del empleo, pero no a la extinción de contratos por esas razones, lo que no implica técnicamente una prohibición de despidos, en el sentido más riguroso de la expresión, sino la ausencia de justa causa. Dicho de otro modo, el despido basado en causas empresariales durante el estado de alarma deberá entenderse como improcedente y no nulo, lo que, en definitiva, supone un incremento del importe de la indemnización de veinte a treinta y tres días, pero no la readmisión como regla general.

En todo caso, el Gobierno apostaba por obstaculizar la extinción de contratos e incentivar las medidas de flexibilidad interna como medio para proteger el empleo. El recurso a las facilidades proporcionadas por los arts. 22 y 23 del Real Decreto-ley 8/2020 no ha sido, en modo alguno, residual, porque las medidas dirigidas a frenar la propagación del COVID-19 han afectado intensamente a la actividad productiva. Muchas empresas debieron cerrar temporalmente por mandato legal ante la suspensión obligatoria de la actividad y otras, si bien pudieron continuar, en modo alguno podían mantener el volumen de negocio o la misma productividad, porque las redes de distribución de productos y materias primas no funcionaban con igual eficacia, y desde luego el volumen de ventas se redujo notablemente en muchos casos. Aunque inicialmente se excluyó de estas medidas a las empresas que pertenecían a un sector incluido en el listado de servicios esenciales, como establecimientos sanitarios o que proporcionan cuidados a personas, el Real Decreto-ley 15/2020 eliminó esa restricción, pues la disposición final octava modificó el art. 22 del Real Decreto-ley 8/2020. Además, ese Real Decreto-ley 15/2020 reformó la Ley sobre Infracciones y

3 Vid. J. A. Fernández Avilés, «¿Es suficiente este derecho laboral excepcional "por aluviones" frente a la pandemia del COVID-19?», Estudios financieros. Revista de Trabajo y Seguridad Social (CEF), núm. 445 (2020), pp. 23 y ss. 
Sanciones en el Orden Social (en adelante, LISOS) para combatir posibles abusos empresariales en la tramitación de estas medidas de flexibilidad.

Por supuesto, el Estatuto de los Trabajadores contempla posibilidades análogas en el art. 47, pero la situación aconsejaba, a juicio del Gobierno, un procedimiento más rápido y eficaz, y por ello el capítulo II del Real Decreto-ley 8/2020 incluyó «medidas de flexibilización de los mecanismos de ajuste temporal de actividad para evitar despidos». El art. 22 de esa norma establece «medidas excepcionales en relación con los procedimientos de suspensión de contratos y reducción de jornada por causa de fuerza mayor» y el art. 23 hace lo propio cuando el empresario invoque causas económicas, organizativas, técnicas o de producción. Conviene señalar que el COVID-19 da lugar a un supuesto específico de fuerza mayor que quizá podría haber encajado en el art. $47 \mathrm{ET}$, pero desde luego la nueva regla legal elimina cualquier incertidumbre sobre la calificación como fuerza mayor, si bien, en todo caso, es necesario demostrar la relevancia del problema y su efectiva relación con la pandemia ${ }^{4}$.

La autoridad laboral juega un relevante papel en el caso de que las medidas descansen en la fuerza mayor, pues debe constatar dicha circunstancia, pero corresponde a la empresa la «decisión sobre la aplicación de medidas de suspensión de los contratos o reducción de jornada, que surtirán efectos desde la fecha del hecho causante de la fuerza mayor». Es sabido que, en la práctica, la autoridad laboral no ha apreciado fuerza mayor en todos los casos, e incluso ha rechazado las medidas por falta de proporcionalidad. Esa clase de decisiones a buen seguro generarán conflictividad, máxime si se ponen en relación con el muy breve plazo para decidir (cinco días), pues una vez transcurrido deberían entrar en juego los efectos del silencio, positivo en principio.

En el caso de que se autoricen las medidas, y en particular la suspensión de contratos, el art. 24 del Real Decreto-ley 8/2020 contempla un alivio económico en forma de reducción o supresión de cotizaciones, pues no tendrán que cotizar las empresas con menos de 50 trabajadores, mientras que las de menor tamaño únicamente deberán ingresar el 25 por 100 de las cuotas patronales (la cotización correspondiente al trabajador se mantiene).

La empresa puede, asimismo, invocar causas económicas, organizativas, técnicas o de producción para acometer estos ajustes, y en principio

${ }^{4}$ Vid. J. Lahera Forteza y R. MATeO Escobar, Políticas para mitigar el impacto laboral $y$ social del Covid-19 en el periodo de transición, ESADE, 2020, disponible en bttps://www. esade.edu/itemsweb/research/EsadeEcPol_InDepth_Politicas_mitigacion.pdf. 
resultan aplicables las reglas generales del Estatuto de los Trabajadores, si bien el art. 23 del Real Decreto-ley 8/2020 introduce especialidades para respetar plenamente los derechos de los trabajadores en empresas que no cuenten con representación unitaria. En tal caso, la comisión representativa que negociará durante el periodo de consultas estará integrada por una persona designada por cada sindicato más representativo y suficientemente representativo del «sector al que pertenezca la empresa y con legitimación para formar parte de la comisión negociadora del convenio colectivo de aplicación». En su defecto, la comisión «estará integrada por tres trabajadores de la propia empresa elegidos conforme a lo recogido en el art. 41.4 del Estatuto de los Trabajadores». El procedimiento se simplifica, pues los plazos se reducen y el periodo de consultas no puede exceder de siete días. Los eventuales conflictos deben tramitarse conforme a la modalidad procesal de conflicto colectivo, tal y como dispone el art. 6 del Real Decretoley 16/2020, de 28 de abril.

Conviene destacar que la disposición adicional sexta del Real Decretoley $8 / 2020$ condiciona estas medidas extraordinarias en el ámbito laboral «al compromiso de la empresa de mantener el empleo durante el plazo de seis meses desde la fecha de reanudación de la actividad», previsión que con toda seguridad también resultará conflictiva — ya ha sido objeto de varias consultas a la Dirección General de Trabajo- ${ }^{5}$ tanto por la determinación del número mínimo de trabajadores como por las causas de extinción de los distintos contratos, amén de que las consecuencias del incumplimiento tampoco son nítidas. Las dudas se alimentan al comprobar que la disposición adicional decimocuarta del Real Decreto-ley 11/2020, de 31 de marzo, se decanta por una valoración casuística «en atención a las características específicas de los distintos sectores y la normativa laboral aplicable, teniendo en cuenta, en particular, las especificidades de aquellas empresas que presentan una alta variabilidad o estacionalidad del empleo o una relación directa con eventos o espectáculos concretos, como sucede, entre otros, en el ámbito de las artes escénicas, musicales, cinematográficas y audiovisuales».

Se precisa, asimismo, que la extinción ordinaria de un contrato de duración determinada no supone incumplimiento de ese compromiso, lo que en último término demuestra que será necesaria alguna clarificación adicional, bien a través de norma, bien por los tribunales. En todo caso, resulta significativo que a tenor de la Exposición de Motivos de

${ }_{5}$ Vid. http://www.eduardorojotorrecilla.es/2020/04/covid19-sobre-la-clausula-de.html. 
ese Real Decreto-ley 11/2020 este compromiso no se considere como un auténtico compromiso, sino como la «voluntad de la empresa de mantener el empleo durante el plazo de seis meses desde la finalización de las medidas de reducción de jornada o suspensión de contratos basadas en el COVID-19» ${ }^{6}$.

En fin, debe, asimismo, tenerse en cuenta que el art. 5 del Real Decretoley $9 / 2020$, de 27 de marzo, estableció una protección especial para los contratos de duración determinada que fueran objeto de suspensión por fuerza mayor o causas económicas, organizativas, técnicas o de producción por las vías que se acaban de indicar. En estos supuestos la duración del contrato se interrumpía, articulándose una especie de paréntesis, de modo que el contrato no podía extinguirse durante la suspensión al haberse paralizado la duración, y, por tanto, debía reanudarse en el mismo punto una vez concluida esa suspensión. Esas eran reglas generales, que fueron acompañadas de medidas de la misma índole para personal docente universitario y también para investigadores ${ }^{7}$.

\section{PERMISO RETRIBUIDO EXTRAORDINARIO PARA TRABAJADORES EN ACTIVIDADES NO ESENCIALES}

Como regla general, la suspensión o paralización de actividades presenciales durante el estado de alarma implicaba o bien su continuidad mediante trabajo a distancia, o bien la suspensión del contrato por fuerza mayor en los términos que se indicaron en el epígrafe anterior. Sin embargo, la primera prórroga del estado de alarma vino acompañada de una medida diferente, más imaginativa, pero sin duda también problemática, y que se relacionaba con un mayor endurecimiento de las condiciones del confinamiento.

En efecto, el Gobierno decidió suspender las actividades en sectores no esenciales desde el 30 de marzo al 9 de abril. Evidentemente, los trabajos a distancia estaban permitidos, pero no los presenciales, salvo los «estrictamente imprescindibles con el fin de mantener la actividad indispensable» ${ }^{8}$. Sin embargo, y a diferencia de lo que había ocurrido en la primera quincena del estado de alarma, el Real Decreto-ley 10/2020, de 29 de marzo, no remitió a procedimientos de regulación de empleo,

\footnotetext{
${ }^{6}$ En general, vid. C. Aragón Gómez (coord.), Impacto del COVID-19 en materia laboral y de Seguridad Social, Madrid, Francis Lefebvre, 2020, pp. 9 y ss.

7 Vid. disposiciones adicionales duodécima y decimotercera del Real Decreto-ley 11/2020.

${ }^{8}$ Art. 4 del Real Decreto-ley 10/2020.
} 
sino que configuró un «permiso retribuido recuperable, de carácter obligatorio, entre el 30 de marzo y el 9 de abril de 2020, ambos inclusive», de modo que los trabajadores conservaban el derecho al salario íntegro, como si continuaran prestando servicios, pero habrán de recuperar esas horas durante el año 2020, debiendo negociarse el modo de recuperación de ese tiempo entre el empleador y los representantes (arts. 2 y 3), aunque en defecto de representantes se debe articular una representación específica en los mismos términos antes indicados para los procedimientos de regulación de empleo por causas económicas, organizativas, técnicas o de producción. Es decir, la comisión representativa que negociará durante el periodo de consultas habrá de estar compuesta por una persona designada por cada sindicato más representativo y suficientemente representativo del «sector al que pertenezca la empresa y con legitimación para formar parte de la comisión negociadora del convenio colectivo de aplicación». En su defecto, la comisión «estará integrada por tres trabajadores de la propia empresa, elegidos conforme a lo recogido en el art. 41.4 del Estatuto de los Trabajadores».

Esta es una medida que afectaba a los sectores no esenciales que debían cesar su actividad durante ese periodo de dos semanas, ofreciendo el anexo del Real Decreto-ley 10/2020 un amplio listado de sectores esenciales - que eran los únicos que podían continuar-; catálogo en verdad muy numeroso donde se incluían, entre otros, el transporte; los establecimientos sanitarios; las fuerzas y cuerpos de seguridad; la distribución de agua, gas y electricidad; las gasolineras; los puertos y aeropuertos; la alimentación; los servicios financieros, y el asesoramiento jurídico. En cualquier caso, se trataba de una lista no exhaustiva que podía ser modificada por el Gobierno, lo que derivó en su ampliación mediante la inclusión de determinados servicios sanitarios ${ }^{9} \mathrm{y}$ de protección de las víctimas de violencia de género ${ }^{10}$.

Es probable que este permiso retribuido también suscite litigiosidad en un futuro cercano, bien sea por el cálculo de la retribución durante el permiso, en especial en caso de complementos variables, o por el modo de recuperación, porque el acuerdo no se producirá en todos los casos y porque esa recuperación debe respetar los límites ordinarios de jornada y no siempre se acomodará bien a circunstancias concretas de los trabajadores (por ejemplo, en supuestos de responsabilidades familiares, porque la

9 Vid. Orden SND/310/2020, de 31 de marzo, por la que se establecen como servicios esenciales determinados centros, servicios y establecimientos sanitarios.

${ }_{10}$ Vid. Real Decreto-ley 12/2020, de 31 de marzo, de medidas urgentes en materia de protección y asistencia a las víctimas de violencia de género. 
recuperación de esas horas podría ser difícilmente compatible con el ejercicio de ciertos derechos de conciliación). Además, la extinción de contratos antes de que las horas hayan sido efectivamente recuperadas daría al empleador derecho a la pertinente compensación para evitar el enriquecimiento injusto del trabajador, pero no es claro el modo de proceder a ella.

\section{LA INTENSIFICACIÓN DE LA ACCIÓN PROTECTORA DE LA SEGURIDAD SOCIAL}

Como no podía ser de otro modo, el sistema de Seguridad Social debe desempeñar un papel decisivo en un contexto como el derivado de la crisis sanitaria producida por el COVID-19. El notable impacto en el empleo provoca una reducción o pérdida de salarios que ha de ser compensada mediante las vías naturalmente destinadas para ello y la Seguridad Social ha de asumir un protagonismo claro.

Por supuesto, la protección por desempleo ha de ocupar una posición principal, pues las reducciones de jornada o suspensiones de contrato derivadas del confinamiento provocan un quebranto económico para los trabajadores que exige la debida atención ${ }^{11}$. Sin embargo, las reglas legales ordinarias no se acomodan del todo bien a una situación excepcional, y por ello es razonable que se hayan introducido las pertinentes matizaciones y adaptaciones. En este sentido, los arts. 25 y siguientes del Real Decreto-ley 8/2020 flexibilizan notablemente el acceso a la protección por desempleo de los trabajadores afectados por medidas de regulación de empleo durante el estado de alarma (con particularidades para los fijos-discontinuos), pues se exime de la acreditación del periodo previo de carencia previsto con carácter general en el art. 266 LGSS (360 días en los seis años anteriores al hecho causante), y este tiempo de disfrute no computa «a los efectos de consumir los periodos máximos de percepción establecidos». Asimismo, se dulcifica el procedimiento, flexibilizando plazos, y esta protección pública se acompaña de facultades de «disponibilidad excepcional» de los derechos consolidados en planes de pensiones en los términos de la disposición adicional vigésima del Real Decreto-ley 11/2020 y del art. 23 del Real Decreto-ley 15/2020, que limi-

${ }^{11}$ Vid. E. E. Taléns ViscontI, «Análisis de las medidas de Seguridad Social adoptadas por el Gobierno de España en relación con la crisis del COVID-19», Estudios financieros. Revista de Trabajo y Seguridad Social (CEF), núm. 445 (2020), pp. 121 y ss. 
tan esa disponibilidad en atención a los «salarios netos dejados de percibir mientras se mantenga la vigencia del ERTE».

Esta mayor generosidad en la protección por desempleo se aprecia, asimismo, en la ampliación del catálogo de situaciones legales de desempleo, pues el art. 22 del Real Decreto-ley 15/2020 considera cumplida esa exigencia cuando el contrato se extinga durante el estado de alarma a instancia de la empresa en el transcurso del periodo de prueba, sin que se valore la causa por la que se hubiera extinguido la relación laboral anterior. Recuérdese que el art. 267.1.a).7 LGSS condiciona la protección por desempleo en esa circunstancia a que «la extinción de la relación laboral anterior se hubiera debido a alguno de los supuestos contemplados en este apartado o haya transcurrido un plazo de tres meses desde dicha extinción». Parece claro, aunque el precepto no lo indique expresamente, que ese plazo de tres meses no es aplicable durante el estado de alarma, pues su exigencia es incompatible con una interpretación teleológica.

Ese mismo art. 22 del Real Decreto-ley 15/2020 considera también en situación legal de desempleo a quienes voluntariamente extinguieron un contrato de trabajo — dimisión, por tanto- a partir del día 1 de marzo para incorporarse a otro empleo por contar con un «compromiso firme de suscripción de un contrato laboral por parte de otra empresa», compromiso que no se materializó a consecuencia de la crisis sanitaria. Se valora, por tanto, la voluntad de trabajar y las escasas opciones de encontrar otro empleo en estas circunstancias excepcionales. Nótese que en ambos casos - esta dimisión con expectativa frustrada de nuevo empleo y la decisión empresarial extintiva durante el periodo de prueba- se trata de una dulcificación del concepto de situación legal de desempleo y no de una exención total de cualesquiera requisitos, principalmente el periodo de carencia, que sigue operativo salvo regla legal expresa en contrario.

Los trabajadores con contratos de duración determinada plantean una problemática particular por la mayor dificultad en algunos casos para acreditar el periodo mínimo de carencia. Las medidas de flexibilización no han eximido ni rebajado ese requisito - excepto para los afectados por medidas de regulación de empleo, como se dijo—, sino que el art. 33 del Real Decreto-ley 11/2020 creó un «subsidio excepcional» para compensar la imposibilidad práctica de encontrar un nuevo empleo durante el confinamiento. Para convertirse en beneficiario de este subsidio, condicionado a carencia de rentas, es imprescindible que el contrato temporal que se extingue durante el estado de alarma hubiera durado al menos 
dos meses. Este subsidio tiene un importe de 430,27 euros y una duración de un mes.

En una línea similar, la protección por desempleo se ha extendido también a los empleados de hogar, pese a que están excluidos de ella con carácter general. En este contexto de emergencia sanitaria el art. 30 del Real Decreto-ley 11/2020 crea un «subsidio extraordinario por falta de actividad para las personas integradas en el Sistema Especial de Empleados de Hogar del Régimen General de la Seguridad Social», al que se puede acceder tanto en el supuesto de extinción del contrato como en el de cese temporal de actividad «a fin de reducir el riesgo de contagio, por causas ajenas a su voluntad, en uno o varios domicilios y con motivo de la crisis sanitaria del COVID-19». El importe del subsidio, que se percibe por periodos mensuales, «será el resultado de aplicar un porcentaje del setenta por ciento a la base reguladora referida, y no podrá ser superior al Salario Mínimo Interprofesional, excluida la parte proporcional de las pagas extraordinarias», debiendo percibirse proporcionalmente a la reducción de jornada en el caso de pérdida parcial de la actividad.

Pese a la evidente extensión extraordinaria de la protección por desempleo en este nuevo contexto, resulta evidente que no todas las personas que han perdido el empleo han podido disfrutar de un ingreso por esta vía. Algunas Comunidades Autónomas, en virtud de sus competencias en materia de asistencia social, han aprobado prestaciones específicas para trabajadores con bajos ingresos afectados por medidas de regulación de empleo o que han sufrido una reducción de ingresos (por ejemplo, Valencia ${ }^{12}$ y Castilla y León ${ }^{13}$ ), así como en general para personas en situación de necesidad ${ }^{14}$.

La protección por desempleo es, sin lugar a dudas, el ámbito de la Seguridad Social que ha merecido mayor atención del Gobierno durante esta coyuntura, pero también cabe reseñar alguna otra actuación. En particular,

12 Vid. Decreto-ley 3/2020, de 10 de abril, de adopción de medidas urgentes para establecer ayudas económicas a los trabajadores y las trabajadoras afectados por un ERTE, y a los que han reducido la jornada laboral por conciliación familiar con motivo de la declaración del estado de alarma por la crisis sanitaria provocada por la COVID-19 (DOGV, 11 de abril de 2020).

${ }_{13}$ Vid. Decreto-ley 2/2020, de 16 de abril, de medidas urgentes y extraordinarias para la protección de las personas y las empresas de Castilla y León frente al impacto económico y social del COVID-19 (BOCL, 18 de abril de 2020).

14 Vid. Decreto-ley 14/2020, de 28 de abril, por el que se adoptan medidas en relación con el sistema sanitario integral de utilización pública de Cataluña, en el ámbito tributario y social, para paliar los efectos de la pandemia generada por la COVID-19 y de adopción de otras medidas urgentes con el mismo objetivo (DOGC, 29 de abril de 2020). 
la consideración como contingencia profesional —asimilación a accidente de trabajo- de las bajas médicas a consecuencia del COVID-19, inclusive del confinamiento preventivo ante la pertinente sospecha, supone una protección más generosa en estos casos, con repercusión tanto en el inicio de los efectos económicos del subsidio (desde el primer día) como en el importe (inclusión de horas extraordinarias en la base reguladora y porcentaje del 75 por 100 ${ }^{15}$. Conviene tener presente que esta asimilación a contingencias profesionales alcanza únicamente a la incapacidad temporal y no al resto de prestaciones (IP o, más probablemente, muerte y supervivencia), donde el COVID-19 será considerado como una enfermedad común, salvo, claro está, que se cumplan las condiciones establecidas por los apartados $e$ ) a $g$ ) del art. 156.2 LGSS para que pueda calificarse como accidente de trabajo, o, incluso, como enfermedad profesional cuando sea contraída por personal sanitario a consecuencia de su trabajo (apartado 3.A.01 del cuadro de enfermedades profesionales contenido en el RD 1299/2006) ${ }^{16}$.

15 «Con el objeto de proteger la salud pública, se considerarán, con carácter excepcional, situación asimilada a accidente de trabajo, exclusivamente para la prestación económica de incapacidad temporal del sistema de Seguridad Social, aquellos periodos de aislamiento o contagio de las personas trabajadoras provocados por el virus COVID-19, salvo que se pruebe que el contagio de la enfermedad se ha contraído con causa exclusiva en la realización del trabajo en los términos que señala el art. 156 del texto refundido de la Ley General de la Seguridad Social, aprobado por el Real Decreto Legislativo 8/2015, de 30 de octubre, en cuyo caso será calificada como accidente de trabajo. Con el mismo carácter excepcional, con efectos desde el inicio de la situación de restricción de la salida del municipio donde tengan el domicilio, y mediante el correspondiente parte de baja, se extenderá esta protección a aquellos trabajadores que se vean obligados a desplazarse de localidad para prestar servicios en las actividades no afectadas por el Real Decreto 463/2020, de 14 de marzo, por el que se declara el estado de alarma para la gestión de la situación de crisis sanitaria ocasionada por el COVID-19, siempre que por la autoridad competente se haya acordado restringir la salida de personas del municipio donde dichos trabajadores tengan su domicilio y les haya sido denegada de forma expresa la posibilidad de desplazarse por la autoridad competente, no puedan realizar su trabajo de forma telemática por causas no imputables a la empresa para la que prestan sus servicios o al propio trabajador y no tengan derecho a percibir ninguna otra prestación pública». Cfr. art. 5 del Real Decreto-ley 6/2020, de 10 de marzo, por el que se adoptan determinadas medidas urgentes en el ámbito económico y para la protección de la salud pública.

16 Vid. C. Gala Durán, «Las medidas adoptadas en materia de Seguridad Social y conciliación de la vida laboral y familiar en relación con la crisis del coronavirus COVID-19», La Administración Práctica, núm. 5 (2020), pp. 49-62. 


\section{MEDIDAS SECTORIALES}

El COVID-19 ha provocado una crisis sanitaria de enorme envergadura y ha puesto a prueba la fortaleza del sistema de salud. En ese marco no solo se han apreciado carencias materiales, sino que los recursos humanos han sido en ocasiones insuficientes para hacer frente a las necesidades, y por ello no es extraño que se hayan aprobado medidas de emergencia en orden a facilitar la contratación de personal.

En este sentido, la Orden SND/232/2020, de 15 de marzo, y la Orden SND/319/2020, de 1 de abril, permitieron el trabajo ordinario de personas en formación ${ }^{17}$, posponiendo determinadas evaluaciones para que pudieran cumplir ese cometido, así como la contratación de personas que aún no estaban en disposición del título. Además, también se relajaban las exigencias para la contratación de personal sanitario procedente de Estados no miembros de la UE, tanto a nivel estatal como en el ámbito autonómico ${ }^{18}$, y se permitía el retorno a la actividad de sanitarios ya jubilados, admitiendo la compatibilidad de la retribución con la pensión ${ }^{19}$.

Junto a esas reglas vinculadas a la contratación también se contemplaban otras con una finalidad estrictamente de ajuste de las condiciones de trabajo para adaptarse a las circunstancias cambiantes provocadas por la crisis sanitaria. En este sentido, la Orden SND/295/2020, de 26 de marzo, introducía medidas en materia de recursos humanos en el ámbito de los servicios sociales, y que en esencia permitían al empleador imponer a los trabajadores - salvo en caso de mujeres embarazadas- cambios en las condiciones de trabajo (asignación de nuevas funciones, movilidad geográfica, etc.) para garantizar los pertinentes cuidados a los usuarios de esos servicios (ancianos, discapacitados, víctimas de violencia de género). Estas facultades extraordinarias del empleador podían incidir en las reglas sobre descansos e interrupciones, inclusive las vacaciones, así como en las personas que desarrollasen trabajo a distancia, pues se permitía el llamamiento para realizar trabajo presencial.

Con un objetivo muy similar, el art. 27 del Real Decreto-ley 16/2020 facilita cambios en la jornada de trabajo del personal al servicio de la Administración de Justicia, pues la actividad de los tribunales se ralentizó

17 Vid. Orden SND/346/2020, de 15 de abril.

${ }^{18}$ En relación con Extremadura, vid. Decreto-ley 5/2020, de 3 de abril, por el que se aprueban medidas urgentes y extraordinarias en materia de política social y sanitaria.

19 Disposición adicional decimoquinta del Real Decreto-ley 11/2020. 
sustancialmente con el estado de alarma. Sin embargo, se trata de medidas no totalmente concretadas y pendientes, asimismo, de la intervención de las Comunidades Autónomas. Con ese mismo propósito de poner en marcha nuevamente la maquinaria judicial, el art. 28 de esa norma permite que los letrados de la Administración de Justicia en prácticas realicen funciones de sustitución y refuerzo, en una medida con claros paralelismos con lo sucedido en el sector sanitario.

El tiempo de trabajo en el transporte terrestre, sector esencial, también se ha visto afectado, en particular las reglas sobre descanso. Tras la pertinente autorización de la Comisión Europea, algunos de los descansos mínimos previstos en el Reglamento 561/2006 fueron temporalmente sustituidos por otros. La Resolución de 26 de marzo de 2020 de la Dirección General de Transporte Terrestre ${ }^{20}$ acometió esa operación para el periodo entre el 29 de marzo y el 12 de abril, mientras que la Resolución de 14 de abril de $2020^{21}$ hizo lo propio con el periodo de 13 de abril a 31 de mayo ${ }^{22}$.

El sector agrícola, considerado esencial por razones de abastecimiento alimentario, se ha visto especialmente perjudicado por la crisis sanitaria y el confinamiento, pues la falta de mano de obra ha puesto en peligro las campañas agrícolas de determinadas frutas y verduras. El Real Decretoley 13/2020, de 7 de abril, introdujo medidas para reducir el impacto negativo. En esencia, se admite la compatibilidad excepcional de la protección por desempleo con el trabajo en la agricultura hasta 30 de junio de 2020. Se pretende con ello que las personas afectadas por procesos de regulación de empleo, y en particular por la suspensión de contratos de trabajo debido al COVID-19, se incorporen a las campañas agrícolas. Estas medidas de flexibilización también alcanzan a extranjeros cuya autorización para

${ }^{20}$ BOE de 27 de marzo.

${ }^{21}$ BOE de 15 de abril.

${ }^{22}$ En concreto, se procede a la sustitución temporal de determinados descansos previstos en el Reglamento núm. 561/2006 para el transporte de mercancías: a) art. 6.1: se sustituye el límite de conducción diaria máximo de nueve horas por uno de once horas; $b$ ) art. 8.1: se reducen los requisitos del descanso diario de once horas por uno de nueve horas (también para el transporte discrecional de viajeros que desarrollen su actividad en el sector agrícola); c) art. 8.6: posibilidad de tomar dos descansos semanales reducidos consecutivos de al menos veinticuatro horas, siempre que o el conductor tome al menos cuatro periodos de descanso semanales en esas cuatro semanas consecutivas, de los cuales al menos dos tendrán que ser periodos de descanso semanales normales de al menos cuarenta y cinco horas, o no se requiere compensación de los descansos semanales reducidos; $d$ ) art. 8.8: se permite que el conductor tome su descanso semanal normal en el vehículo, siempre y cuando el vehículo vaya adecuadamente equipado para el descanso de cada uno de los conductores y esté estacionado. 
trabajar se extinga antes del 30 de junio y a extranjeros en situación regular entre dieciocho y veintiún años.

Los trabajadores autónomos son destinatarios de medidas específicas, algunas para reducir costes en momentos de escaso o nulo rendimiento de la actividad, como moratorias en el pago de cotizaciones ${ }^{23}$, y otras para garantizar ingresos, destacando sin duda la prestación extraordinaria por cese de actividad ${ }^{24}$. Algunas Comunidades Autónomas han creado, asimismo, prestaciones específicas dirigidas a trabajadores por cuenta propia ${ }^{25}$.

En fin, también conviene poner de manifiesto que la formación profesional ha debido adaptarse a las nuevas circunstancias, y en particular a la suspensión de la docencia presencial, lo que supone, en esencia, que deben articularse modalidades de formación a distancia. En este sentido, la Resolución de 15 de abril de 2020 del Servicio Público de Empleo Estatal ${ }^{26}$ permite impartir la acción formativa en su totalidad mediante «aula virtual», y, pese a su carácter virtual, tiene la consideración de formación presencial (art. 3). No obstante, la formación profesional verdaderamente presencial se admite expresamente en algunos ámbitos, como sucede con el personal ferroviario ${ }^{27}$.

\section{CONSIDERACIONES FINALES}

El COVID-19 ha desembocado en la adopción de numerosas medidas en un muy corto espacio de tiempo. La aprobación de reales decretos-ley y órdenes ministeriales se sucede, y el contenido es muy heterogéneo, pues se mezclan actuaciones en ámbitos y sectores muy diversos (fiscal, laboral, vivienda, sanidad, consumidores, seguridad social, etc.). Además, la vigencia de las medidas incluidas en esas normas omnibus no siempre es muy extensa, pues algunas reglas apenas duran días antes de sufrir modificaciones. La situación fáctica es cambiante y es fácil detectar un alto grado de improvisación por la necesidad de una reacción inmediata.

23 Art. 34 del Real Decreto-ley 11/2020.

24 Art. 17 del Real Decreto-ley 8/2020.

${ }^{25}$ Como Andalucía (Decreto-ley 9/2020, de 15 de abril, por el que se establecen medidas urgentes complementarias en el ámbito económico y social como consecuencia de la situación ocasionada por el coronavirus) y Castilla y León (Decreto-ley 2/2020, de 16 de abril, de medidas urgentes y extraordinarias para la protección de las personas y las empresas de Castilla y León frente al impacto económico y social del COVID-19).

${ }^{26}$ BOE del 17 de abril.

27 Vid. Orden TMA/379/2020, de 30 de abril. 
Aunque muchas de las medidas tienen un carácter social, pues se dirigen a cubrir necesidades básicas y evitar daños permanentes en la organización vital de las personas, como nítidamente se aprecia en las que afectan a la vivienda, a nuestros efectos solo procede valorar las que inciden propiamente en el contexto laboral y de seguridad social, y que se caracterizan, en su mayor parte, porque no parecen tener —al menos inicialmente- vocación de permanencia, sino que construyen un ordenamiento coyuntural y en cierto modo paralelo al ordinario. Se conciben como remedio a una crisis y no como reformas estructurales llamadas a sustituir a la regulación vigente. Sin embargo, tampoco cabe descartar que la evolución de los acontecimientos derive en una duración mucho más larga de la prevista y que algunas medidas acaben desplazando a las ahora estructurales.

Sin lugar a dudas, muchas de las actuaciones pueden ser comprensibles en el contexto extraordinario de esta crisis sanitaria. Sin embargo, una valoración estrictamente jurídica arroja incertidumbres, y, a buen seguro, en el futuro se cuestionará el alcance de las facultades del Gobierno durante el estado de alarma, porque el art. 11 de la LO 11/1981 va a requerir una interpretación generosa para acomodar algunas de las reglas laborales aprobadas desde el 14 de marzo. Por ejemplo, la prohibición de despidos es más que razonable desde un punto de vista humano, y desde luego un propósito legítimo desde una perspectiva jurídico-laboral ${ }^{28}$, pues la protección del empleo, por ejemplo, debe ser un objetivo en este contexto, como ha puesto de manifiesto la OIT ${ }^{29}$. No obstante, el TC habrá de elaborar una interpretación ingeniosa para justificar las limitaciones a los poderes empresariales, porque las prerrogativas del Gobierno durante el estado de alarma no parecen tener tal alcance, al menos en apariencia. Quizá en esa argumentación deba dotarse de singular fuerza al art. 1.1 $\mathrm{CE}$, y en concreto al carácter de Estado social que ese precepto atribuye a nuestro país.

Más dudas incluso presenta la extensión de determinadas reglas a un periodo posterior a la finalización del estado de alarma — tres meses, según la norma vigente a 30 de abril—, pues habrá que determinar si es posible que esas medidas extraordinarias mantengan vigencia en un contexto ordinario y, en caso de respuesta afirmativa, durante cuánto tiempo, debiendo acudirse a un test de constitucionalidad donde la valoración de la propor-

\footnotetext{
28 Vid. J. M. SeRvaIs, «El COVID-19. ¿Qué nos dice la OIT?», disponible en bttp:// www.cielolaboral.com/wp-content/uploads/2020/04/oit_noticias_cielo_coronavirus.pdf.

29 bttps://www.ilo.org/global/topics/coronavirus/impacts-and-responses/lang-en/index.htm.
} 
cionalidad será determinante ${ }^{30}$. Piénsese, por ejemplo, en la flexibilización de las reglas del trabajo a distancia, modalidad que aparentemente no requiere consentimiento del trabajador durante el estado de alarma y donde las obligaciones de prevención de riesgos laborales parecen también temporalmente inoperantes. Y todo ello, por supuesto, sin olvidar, por un lado, los litigios competenciales propios de un Estado descentralizado, y, por otro, el carácter urgente y la extraordinaria necesidad de todas y cada una de las medidas adoptadas, pues el estado de alarma no conlleva una flexibilización o anulación de las exigencias para la aprobación de un real decreto-ley. Por señalar un ejemplo gráfico, es claro que no concurría el presupuesto habilitante en el cambio de ente gestor del Régimen de Clases Pasivas operado por el Real Decreto-ley 15/2020, y que esa no es una medida que en modo alguno venga impuesta por el COVID-19.

Se avecinan, así pues, meses —años más bien— de litigios judiciales que contribuirán a depurar una normativa que, en líneas generales, parece necesaria para abordar una situación tan excepcional, pero que se dicta en un contexto de incertidumbre jurídica por la falta de precedentes — de manera análoga a lo sucedido con la aplicación del art. 155 de la Constitucióny con un grado de premura tal que hace inevitables las deficiencias técnicas y ciertas incoherencias. Es probable que el Tribunal Constitucional, que en último término tendrá la última palabra, acepte la mayor parte de las medidas aprobadas durante el estado de alarma — si no todas-, precisamente por esa situación de excepcionalidad, pero también que muestre más reticencias a su prolongación una vez que finalice formalmente dicho estado. Para elaborar su respuesta seguramente deba matizar la doctrina de su Sentencia 83/2016, de 28 de abril, que parecía reservar las limitaciones más intensas de derechos a los estados de excepción y de sitio $^{31}$, aunque desde luego el conflicto de los controladores aéreos tenía pocos paralelismos con la situación actual. El problema jurídico, por consiguiente, es de notable envergadura, pero la respuesta final se demorará algunos años todavía, y no solo habrá que dilucidar las cuestiones propiamente constitucionales, sino que es previsible que se multipliquen las demandas solicitando responsabilidad patrimonial de la Administración en ámbitos muy diferentes (sanitario, empresarial, laboral, etc.).

30 Vid. V. Álvarez García, «El coronavirus (COVID-19): respuestas jurídicas frente a una situación de emergencia sanitaria», El Cronista, núm. 86-87 (2020), pp. 6 y ss.

${ }^{31} \mathrm{Vid}$. A. NogueIRA López, «Confinar el coronavirus. Entre el viejo derecho sectorial y el derecho de excepción», El Cronista, núm. 86-87 (2020), pp. 6 y ss. 